\title{
Genetic Markers Association in Autism Spectrum Disorder
}

\section{Nadra E Elamin ${ }^{1 *}$ and Laila Y AL-Ayadhi ${ }^{1,2}$}

${ }^{1}$ Autism Research and Treatment Center, Shaik AL-Amodi Autism Research Chair, Department of Physiology, Faculty of Medicine, King Saud University, Saudi Arabia ${ }^{2}$ Department of Physiology, Faculty of Medicine, King Saud University, Riyadh, Saudi Arabia

\begin{abstract}
Although the etiology of autism spectrum disorder (ASD) is still unclear, multiple factors have been suggested to be involved in its pathogenesis. There is a strong evidence for multiple interacting genetic factors as the main cause of autism. Hundreds of genes and genetic mutations that are involved in autism development were identified, and thus serve as useful genetic markers for identification of autism. Those genes play a key role in brain development, or may code for immune proteins. Numerous studies have suggested that autism can be inherited based on earlier twins studies which showed that monozygotic (MZ) twins had higher concordance rates than dizygotic (DZ) twins for ASDs. In this review we consider the genetic factors that underlie the pathogenesis of autism and their contribution to the disease outcome. In conclusion, candidate genes studies will highlight the role of interaction between innate immunity and neuronal activity in the etiology of autism, and it may lead to earlier diagnosis and behavioral intervention which improves ASD subjects outcomes.
\end{abstract}

Keywords: Autism; Genetic markers; Neurodevelopment; Candidate genes

\section{Introduction}

Autism spectrum disorder (ASD) is a severe neurodevelopmental and neuropsychiatric disorder characterized by impaired social interaction, verbal and non-verbal communication deficit, and restricted interests and repetitive behavior $[1,2]$. There is a strong male bias, five times more males than females are affected $[3,4]$. Although the etiology of autism is still unclear; multiple factors have been suggested to be involved in its pathogenesis [5].

Autism is considered as one of autoimmune neuropsychiatric disorders. There is a strong evidence suggests that the autoimmunity plays a key role in the pathogenesis of neurodevelopmental disorders, including autism [6-9]. The immune response could play a role in the impairment of the central nervous system (CNS) that characterizes autistic children $[8,10,11]$. In addition, the prenatal maternal-fetal immune interaction was confirmed to affect the fetal brain development [12-14].

Nevertheless, both genetic and environmental factors are believed to contribute to the risk for the development of the disease spectrum during early development $[9,15]$. There is a strong evidence for multiple interacting genetic factors as the main cause of autism [16]. Those genes play a key role in brain development or associated with brain structures and neurotransmitters defects. Moreover, they may code for immune proteins [17] (Figure 1).

Researchers previously have identified hundreds of genes and genetic mutations that are involved in autism development, and served as useful genetic markers for the disease identification. Numerous studies have suggested that autism can be inherited based on earlier twins studies which showed that monozygotic (MZ) twins had higher concordance rates than dizygotic (DZ) twins for ASDs, thus confirming the influence of genetics in the cause of autism [18]. Concordance for ASD between identical twins is higher than in any other cognitive and/ or behavioral disorders $[18,19]$.

In this review we considered the genetic factors that underlie the pathogenesis of autism and their contribution to the disease outcome. A comprehensive search of PubMed database was performed, using multiple terms "autism", "gene", "genetic markers", "chromosomal abnormalities", focusing on the most commonly implicated candidate genes in autism.

\section{The genetics of autism}

Family studies have confirmed the key role of the genetic factors in the most of the idiopathic autism cases [17]. No single gene variant has been identified yet contributed to ASD susceptibility in the majority of the cases, due to the genetic complexity; multiple genetic factors are involved in the majority of cases.

Yuen and colleagues published a new study, using whole-genome sequencing analysis in quartet families. They revealed that genes linked to autism can vary among family members, as the siblings who share a diagnosis of autism carried different ASD-relevant mutations. Only one-third of siblings with autism shared similar genetic variations, which was inherited from one of their parents. This could be due to the fact that many genes are not directly associated with autism; rather they associated with specific psychological and nervous system conditions often characterizing autism [20]. In addition, they showed that the chance to develop autism in identical twins where one twin had autism was higher, because they share the same DNA [20,21].

Different approaches were used to identify common genetic risk factors and chromosomal regions that underlying autism: 1) Whole genome screens to search for common genetic markers associated with autism in multiplex families. 2) Cytogenetic studies that could point to the relevant inherited or de novo chromosomal abnormalities, including gene copy number variations, associated with autism in affected individuals and their families, and 3) Association studies

*Corresponding author: Nadra E Elamin, Autism Research and Treatment Center, Shaik AL-Amodi Autism Research Chair, Department of Physiology, Faculty of Medicine, King Saud University, PO Box 2925,Riyadh 11461, Saudi Arabia, Tel: 00966564902960; E-mail: nadraelyass@hotmail.com

Received September 22, 2015; Accepted October 27, 2015; Published November 06, 2015

Citation: Elamin NE, AL-Ayadhi LY (2015) Genetic Markers Association in Autism Spectrum Disorder. J Clin Med Genomics 3: 132. doi:10.4172/2472-128X.1000132

Copyright: (c 2015 Elamin NE, et al. This is an open-access article distributed under the terms of the Creative Commons Attribution License, which permits unrestricted use, distribution, and reproduction in any medium, provided the original author and source are credited. 


\section{Genetic and possibly Environmental factors}

$$
\downarrow
$$

Alteration in Brain Development
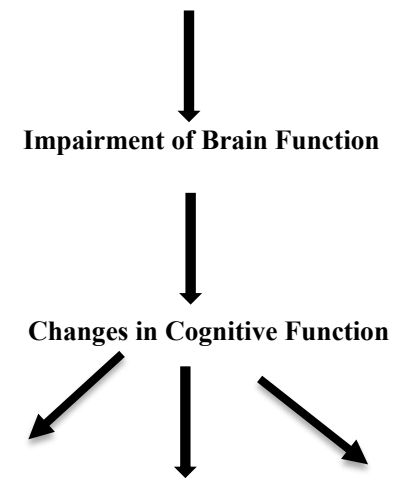

Social Interaction Impairment Communication Deficit Stereotypies

Figure 1: Schematic representation of the effect of the genetic and environmental factors in the outcome of autism.

(candidate genes studies) that could determine the selected candidate genes known to be associated with abnormal brain development or linked to the pathogenesis of autism [22].

\section{Chromosomal abnormalities in autism}

Cytogenetic studies help detection of chromosomal abnormalities to locate relevant genes for autism. A number of maternal duplications, deletions, and insertions have been reported in autistic children [23]. The most frequent chromosomal abnormality is maternal duplication $15 q 11-13$, which accounts for $~ 1-3 \%$ of autism [24], followed by the microdeletion of $16 \mathrm{p} 11.2$ which accounts for $\sim 0.5 \%$ of autistic patients [25]. In addition, other chromosomes have shown to have some linkage to ASD etiology such as chromosomes 2q21-33, 3q2527, 3p25, 4q32, 6q14-21, 7q22, 7q31-36, 11p12-13, 17q11-21 [26]. Most of the genes located in those chromosomes are associated with specific symptoms, such as speech and language disorders, learning and memory deficit, communication and social difficulties, and mental retardation $[21,23,24,26]$. These genes include $E N 2$, Reelin, serotenin transporter gene (5HTT), GABRB3, FOXP2, AVPR1A, UBE3A, and $W N T 2$. Additional candidate genes that may represent risk loci for autism were identified, such as ALDOA, DOC2A, HIRIP3, MAPK3, MAZ, PPP4C, SEZ6L2, and TAOK [25], NRXN1, CNTN4, DPP6, UBE3A, OR4N4 [26].

\section{Candidate genes implicated in autism}

The detection of genetic variants responsible for ASD outcome has thus far been elusive. However, genome wide association studies have identified a growing number of distinct and individually rare genetic variants associated with the disease outcome. Multiplex families studies confirmed the contribution of more than 10 genes in the onset of the disease, but most of them were associated with only one specific symptom suggesting the involvement of multiple genes in the disease [25]. Mutations in the genes active in early development can lead to brain malformations or severe mental retardation. In contrast, postnatal brain development requires input from the environment that triggers the release of neurotransmitter and promotes critical aspects of synaptic maturation [27].

De novo mutation appears to be contributed to the incidence of autism [28]. Genes with de novo mutation include CHD8, DYRK1A, GRIN2B, KATNAL 2, RIMS1, SCN2A, POGZ, ADNP, ARID1B, ANK2, CUL3, TBR1and TBR1 [28-30]. Some of candidate genes play different roles in the pathogenesis of autism, by affecting brain structure and function, mediating different behavioral responses, impairing learning and memory process, impairing motor and cognitive development, impairing speech and language process, or affecting social behaviors. These genes include Engrailed homebox 2 (EN2), Reelin, serotenin transporter gene (5HTT), GABRB3, FOXP2, AVPR1A, UBE3A, WNT2 $[17,21,26,31]$.

De novo mutation in SHANK2 synaptic scaffolding gene was detected in autistic children and it linked to intellectual disability. This mutation may lead to language and social communication disorders [32]. Furthermore, mutation in neuroligin genes NLGN3 and NLGN4 were reported in autistic children, it may affect cell-adhesive molecules at the synapse leading to autism [33].

In addition, the neuronal cell-adhesive molecules cadherin 9 $(\mathrm{CDH} 9)$ and cadherin $10(\mathrm{CDH} 10)$ were implicated in the pathogenesis of autism [34]. Another gene of interest is chromatin helicase gene (CHD8) which regulates brain development and controls expression of many other genes. The loss of function may contribute to autism pathology due to the reduced level of CHD8 protein, which may lead to the disruption of expression of other ASD risk genes regulated by $\mathrm{CHD} 8$ protein [35-37]. Moreover, several studies indicate the involvement of the oxytocin receptor gene $(O T R)$ in the pathophysiology of autism. They reported a low level of oxytocin in the plasma of autistic children; as the physiologic effects of oxytocin (OT) are exerted through its receptor. Furthermore, they postulated its contribution to the social impairment and the development of the repetitive behaviors found in autistic children $[17,38]$.

A recent study has identified a new gene that linked to autism in females, CTNND2, which encodes the adhesive junction-associated $\delta$-catenin protein. It was detected in the fetal brain more than in adults brain or other tissues, thus it may play a critical role in brain development and may be associated with other intellectual disability. Moreover, it regulates other genes functions [4].

Taken together, linkage and candidate gene association studies have implicated several genes and chromosomal regions in autism, although the replication and confirmation of some of these findings was failed. These genes play a key role in brain development, or are associated with brain structure, neurotransmitters, or neuromodulators [17]. Some of these genes are involved in the neuronal cell-adhesion pathway, they are involved in the development of the nervous system and contributed to synaptic formation such as NRXN1, NLGN3, NLGN4, CNTNAP2 [33]. However, mutation in these genes interfere with synaptic development and plasticity, giving rise to wide range of pathologic findings that characterized autism, such as abnormalities in cortical and cerebellar development, learning and memory process deficit, language disabilities and social cognition, behavioral impairment, and increased risk of epilepsy (Table 1).

\section{Immune-related genes}

Several studies have reported an association between some autoimmune disorders and specific human leukocyte antigen (HLA) alleles and related genes which have been identified as susceptibility 


\begin{tabular}{|c|c|c|c|}
\hline Genes & Chromosomal position & Effect of mutation & Reference \\
\hline GABRB3 & $15 q 11.2$ & Learning and memory deficits & {$[17,24]$} \\
\hline FOXP2 & $7 q 31$ & Severe speech and language disorders, social behaviors impairments & [17] \\
\hline AVPRIA & $12 q 14$ & Impaired motor and cognitive development & [26] \\
\hline UBE3A & $15 q 11$ & Learning and memory deficit & {$[17,26]$} \\
\hline WNT2 & $7 q 31$ & Reduced social interaction & {$[17,21,26]$} \\
\hline SEZ6L6 & $16 \mathrm{p} 11$ & Increased risk of epilepsy & [25] \\
\hline NRXN1 & $2 \mathrm{p} 16.3$ & Language disabilities and social cognition & [33] \\
\hline NLGN3 \&NLGN4 & $\mathrm{Xq} 28, \mathrm{Xp22.33}$ & Language disabilities and social cognition & [33] \\
\hline CNTNAP2 & $7 q 35$ & Seizure and language deficit & [25] \\
\hline CHD8 & $14 q 11.2$ & Abnormal neuronal development & {$[35,37]$} \\
\hline EN2 & $7 q 36$ & Brain structure alteration & {$[21,26,31]$} \\
\hline SHANK3 & $22 q 13$ & Development of language and social cognition & {$[25,32]$} \\
\hline CDH9 \&CDH10 & $5 q 14$ & Impaired neuronal development & {$[31,34]$} \\
\hline OXRT & $3 p 26.2$ & Social impairment and development of the repetitive behaviors & {$[24,38]$} \\
\hline CTNND2 & $5 p 15.2$ & Intellectual disability and brain development & [4] \\
\hline 5-HTT & $17 q 12$ & Behavioral impairment & [31] \\
\hline RELN & $7 q 22$ & Learning and memory process deficit & {$[17,25,26,31]$} \\
\hline
\end{tabular}

Table 1: Selected candidate genes associated with ASD and their chromosomal location.

markers for the diseases, such as rheumatoid arthritis, hypothyroidism and type I diabetes, and autism [14,39]. In autism, several HLA alleles located in class I, class II, and class III regions, were found to be implicated in the pathogenesis of autism [40,41]. The mutations and immune dysregulation of certain HLA alleles in the developing brain may lead to the alteration of the brain connectivity and function characterizing autism $[9,42]$.

Early familial studies reported the contribution of DR4 alleles to autism susceptibility, because it may disrupt the normal fetal brain development due to the triggered immune response [12]. Its frequency was increased in their mothers, suggesting the contribution of maternal DR4 to autism $[43,44]$. The reason behind that might be the interaction with other risk alleles factors for autism or environmental factors such as maternal infections and thus affect the brain development in autistic children [12]. Another study confirmed the contribution of DR4 in the disease susceptibility and also suggested a protective role of DR13 [42].

A study carried out by Lee et al. reported an interesting finding; the frequencies of DR4 alleles were significantly increased in autistic children and their mothers in a specific region [14]. This could be attributed to the exposure to some environmental factors or pathologic factors that may stimulate immune response in the mother and fetus, which in turn may lead to the development of autism [14,45].

More recently, HLA-DRB1 alleles including DR4 were associated with autism in Han Chinese population (DR4, DR11, and DR14). Those alleles have different effects on intelligence and neuropsychology tests among autistic children [46]. Recent studies reported different HLA alleles and haplotypes which were associated with autism. Autistic children exhibited a significantly higher frequency of HLADRB $1^{\star} 11$ allele, and a significantly lower frequency of HLA-DRB1 ${ }^{\star} 03$ allele compared to the controls, suggesting a significant risk association of HLA-DRB ${ }^{\star} 11$ with autism, especially in families with history of autoimmune disorders, as well as a protective association of HLA$\mathrm{DRB}^{\star} 03$ [38], unlike Torres et al who reported a protective association of DR13 in Caucasians [43].

Al-Hakbany et al. demonstrated for the first time the association of number of HLA alleles and haplotypes with the disease, HLA-A $* 01$, $A * 02, \mathrm{HLA}-\mathrm{B} * 07, \mathrm{DRB} 1 * 1104$, and the haplotype $A * 02-\mathrm{B} * 07$ were positively associated with autism, whereas DQB $1 * 0202$, DQB $1 * 0302$, and DQB1*0501 were negatively associated with the disease [41]. Furthermore, an association of HLA-C $\mathrm{C}^{\star} 03$ and HLA-DRB1 ${ }^{\star} 01$ alleles has been reported in Macedonian autistic patients. Although some haplotypes, $A^{\star} 11-C^{\star} 12-B^{\star} 52-D R B 1 * 15, A^{\star} 24-C^{\star} 03-B^{\star} 55-D R B 11^{\star} 16$, and $A^{\star} 24-C^{\star} 03-B^{\star} 55-D R B 1^{\star} 16$, were frequently higher in autistic children but they were not statistically significant [47].

Regarding the HLA non-classical genes, the tolerogenic molecule HLA-G is known to be responsible for preventing the destruction of the fetal tissues by the maternal immune system. However, HLA-G/ KIR interaction is responsible for the immune tolerance during pregnancy. The activated HLA/KIR complexes were detected in autistic children and their mothers $[40,48]$; it leads to the neurodevelopmental impairment presented in autism. A recent study showed that a 14 bp insertion polymorphism in the HLA-G gene was significantly associated with autism development due to the prenatal immune activation. The polymorphic gene was detected in autistic children and their mothers and not in their non-autistic siblings, supporting the notion that prenatal immune activation plays an important role in autism development [49].

Furthermore, strong association of the complement C4B null allele in HLA class III region with autism has been reported in several studies [40]. They demonstrated a significant increase in the C4B null allele in autistic children compared to controls [50-52]. Moreover, Mostafa et al. reported an increased risk of autism in the families with autoimmune disorders [52].

\section{Conclusion}

Understanding the etiology of ASD may help in the development of biomarkers for its prediction, diagnosis, prognosis, and eventually in its prevention and intervention. In addition, candidate genes studies will highlight the role of interaction between innate immunity and neuronal activity in the etiology of autism. Moreover, elucidating the genes associated with autism and the effect of their products on brain development will be useful for accurate diagnosis and earlier treatments for children with a genetic predisposition towards autism.

\section{Acknowledgment}

The authors would like to thank the Department of Pharmacology, Faculty of Medicine, for hosting the Autism Research and Treatment Center Lab. facility. 


\section{References}

1. Fombonne E (2009) Epidemiology of pervasive developmental disorders. Pediatr Res 65: 591-598.

2. American Psychiatric Association (APA) (2000) Diagnostic and Statistical Manual of Mental Disorders. American Psychiatric Publishing, Inc; Arlington, VA

3. Autism and Developmental Disabilities Monitoring Network Surveillance Yea 2008 Principal Investigators; Centers for Disease Control and Prevention (2012) Prevalence of autism spectrum disorders--Autism and Developmental Disabilities Monitoring Network, 14 sites, United States, 2008. MMWR Surveil Summ 61: 1-19.

4. Turner TN, Sharma K, Oh EC, Liu YP, Collins RL, et al. (2015) Loss of $\hat{I}^{\prime}$ catenin function in severe autism. Nature 520: 51-56.

5. Ashwood P, Wills S, Van de Water J (2006) The immune response in autism: a new frontier for autism research. J Leukoc Biol 80: 1-15.

6. Patterson PH (2011) Maternal infection and immune involvement in autism. Trends Mol Med 17: 389-394.

7. Singh VK (2009) Phenotypic expression of autoimmune autistic disorder (AAD): a major subset of autism. Ann Clin Psychiatry 21: 148-161.

8. Al-ayadhi LY, Mostafa GA (2011) Increased serum osteopontin levels in autistic children: relation to the disease severity. Brain Behav Immun 25: 1393-1398.

9. Onore C, Careaga M, Ashwood P (2012) The role of immune dysfunction in the pathophysiology of autism. Brain Behav Immun 26: 383-392.

10. Gupta S, Aggarwal S, Rashanravan B, Lee T (1998) Th1- and Th2-like cytokines in CD4+ and CD8+ T cells in autism. J Neuroimmunol 85: 106-109.

11. Ashwood P, Corbett BA, Kantor A, Schulman H, Van de Water J, et al. (2011) In search of cellular immunophenotypes in the blood of children with autism. PLoS One 6: e19299.

12. Warren RP, Singh VK, Cole P, Odell JD, Pingree CB, et al. (1992) Possible association of the extended MHC haplotype B44-SC30-DR4 with autism. Immunogenetics 36: 203-207.

13. Mostafa GA, El-Sherif DF2, Al-Ayadhi LY3 (2014) Systemic auto-antibodies in children with autism. J Neuroimmunol 272: 94-98.

14. Lee LC, Zachary AA, Leffell MS, Newschaffer CJ, Matteson KJ, et al. (2006) HLA-DR4 in families with autism. Pediatr Neurol 35: 303-307.

15. Poot M (2013) Towards identification of individual etiologies by resolving genomic and biological conundrums in patients with autism spectrum disorders. Molecular Syndromology 4: 213-226.

16. Reich DE, Lander ES (2001) On the allelic spectrum of human disease. Trends Genet 17: 502-510.

17. Muhle R, Trentacoste SV, Rapin I (2004) The genetics of autism. Pediatrics 113: e472-486

18. Bailey A, Le Couteur A, Gottesman I, Bolton P, Simonoff E, et al. (1995) Autism as a strongly genetic disorder: evidence from a British twin study. Psychol Med 25 : $63-77$.

19. Rosenberg RE, Law JK, Yenokyan G, McGready J, Kaufmann WE, et al. (2009) Characteristics and concordance of autism spectrum disorders among 277 twin pairs. Arch Pediatr Adolesc Med 163: 907-914.

20. Yuen RK, Thiruvahindrapuram B, Merico D, Walker S, Tammimies $K$, et al. (2015) Whole-genome sequencing of quartet families with autism spectrum disorder. Nat Med 21: 185-191.

21. Matsunami N, Hadley D, Hensel H, Christensen GB, Kim C, et al. (2013) Identification of Rare Recurrent Copy Number Variants in High-Risk Autism Families and Their Prevalence in a Large ASD Population. PLoS ONE 8: e52239.

22. Shaw CA, Sheth S, Li D, Tomljenovic L (2014) Etiology of autism spectrum disorders: Genes, environment, or both?. OA Autism 2: 11.

23. Klauck SM (2006) Genetics of autism spectrum disorder. Eur J Hum Genet 14: 714-720

24. Veenstra-Vanderweele J, Christian SL, Cook EH Jr (2004) Autism as a paradigmatic complex genetic disorder. Annu Rev Genomics Hum Genet 5 : 379-405.
25. Kumar RA, Marshall CR, Badner JA, Babatz TD, Mukamel Z, et al. (2009) Association and mutation analyses of $16 \mathrm{p} 11.2$ autism candidate genes. PLoS One 4: e4582.

26. Freitag CM, Staal W, Klauck SM, Duketis E, Waltes R (2010) Genetics of autistic disorders: review and clinical implications. Eur Child Adolesc Psychiatry 19: $169-178$

27. Morrow EM, Yoo SY, Flavell SW, Kim TK, Lin Y, et al. (2008) Identifying autism loci and genes by tracing recent shared ancestry. Science 321: 218-223.

28. Sanders SJ, Ercan-Sencicek AG, Hus V , Luo R, Murtha MT, et al. (2011) Multiple recurrent de novo CNVs, including duplications of the $7 q 11.23$ Williams syndrome region, are strongly associated with autism. Neuron 70: 863-885.

29. Ronemus M, lossifov I, Levy D, Wigler M (2014) The role of de novo mutations in the genetics of autism spectrum disorders. Nat Rev Genet 15: 133-141.

30. Krumm N, O'Roak BJ, Shendure J, Eichler EE2 (2014) A de novo convergence of autism genetics and molecular neuroscience. Trends Neurosci 37: 95-105.

31. Holt R, Barnby G, Maestrini E, Bacchelli E, Brocklebank D, et al. (2010) Linkage and candidate gene studies of autism spectrum disorders in European populations. Eur J Hum Genet 18: 1013-1019.

32. Berkel S, Marshall CR, Weiss B, Howe J, Roeth R, et al. (2010) Mutations in the SHANK2 synaptic scaffolding gene in autism spectrum disorder and mental retardation. Nat Genet 42: 489-491.

33. Jamain S, Quach $H$, Betancur C, Råstam M, Colineaux C et al. (2003) Mutations of the X-linked genes encoding neuroligins NLGN3 and NLGN4 are associated with autism. Nat Genet 34: 27-29.

34. Wang K, Zhang H, Ma D, Bucan M, Glessner JT, et al. (2009) Common genetic variants on $5 \mathrm{p} 14.1$ associate with autism spectrum disorders. Nature 459: 528 533.

35. Cotney J, Muhle RA, Sanders SJ, Liu L, Willsey AJ, et al. (2015) The autismassociated chromatin modifier $\mathrm{CHD} 8$ regulates other autism risk genes during human neurodevelopment. Nature communication 6: 11.

36. Iossifov I, O'Roak BJ, Sanders SJ, Ronemus M, Krumm N, et al. (2014) The contribution of de novo coding mutations to autism spectrum disorder. Nature 515: 216-221.

37. Bernier R, Golzio C, Xiong B, Stessman HA, Coe BP, et al. (2014) Disruptive CHD8 mutations define a subtype of autism early in development. Cell 158 263-276.

38. Wu S, Jia M, Ruan Y, Liu J, Guo Y, et al. (2005) Positive association of the oxytocin receptor gene (OXTR) with autism in the Chinese Han population. Bio Psychiatry 58: 74-77.

39. Mostafa GA, Shehab AA, Al-Ayadhi LY (2013) The link between some alleles on human leukocyte antigen system and autism in children. J Neuroimmuno 255: 70-74.

40. Torres AR, Westover JB, Rosenspire AJ (2012) HLA Immune Function Genes in Autism. Autism Res Treat 2012: 959073.

41. Al-Hakbany M, Awadallah S, Al-Ayadhi L (2014) The Relationship of HLA Class I and II Alleles and Haplotypes with Autism: A Case Control Study. Autism Res Treat 2014: 242048

42. Needleman LA, McAllister AK (2012) The major histocompatibility complex and autism spectrum disorder. Dev Neurobiol 72: 1288-1301.

43. Torres AR, Maciulis A, Stubbs EG, Cutler A, Odell D (2002) The transmission disequilibrium test suggests that HLA-DR4 and DR13 are linked to autism spectrum disorder. Human Immunology 63: 311-316.

44. Johnson WG, Buyske S, Mars AE, Sreenath M, Stenroos ES, et al. (2009) HLA DR4 as a risk allele for autism acting in mothers of probands possibly during pregnancy. Archives of Pediatrics and Adolescent Medicine 163: 542-546.

45. Patterson PH (2011) Maternal infection and immune involvement in autism Trends Mol Med 17: 389-394.

46. Chien YL, Wu YY, Chen $\mathrm{CH}$, Gau SS, Huang YS, et al. (2012) Association of HLA-DRB1 alleles and neuropsychological function in autism. Psychiatr Genet 22: $46-49$.

47. Trajkovski V, Spiroski M (2015) DNA typing of HLA-A, -C, -B, AND -DRB1 in the children with autism in the Republic of Macedonia. Bratisl Lek Listy 116: 14-19.

48. Guerini FR, Bolognesi E, Chiappedi M, Manca S, Ghezzo A, et al. (2014) 
Citation: Elamin NE, AL-Ayadhi LY (2015) Genetic Markers Association in Autism Spectrum Disorder. J Clin Med Genomics 3: 132. doi:10.4172/2472128X.1000132

Activating KIR molecules and their cognate ligands prevail in children with a diagnosis of ASD and in their mothers. Brain Behav Immun 36: 54-60.

49. Guerini FR, Bolognesi E, Chiappedi M, Ghezzo A, Canevini MP, et al. (2015) An HLA-G/14bp insertion/deletion polymorphism associates with the development of autistic spectrum disorders. Brain, Behavior, and Immunity 44: 207-212.

50. Warren RP, Singh VK, Cole P, Odell JD, Pingree CB, et al. (1991) Increased frequency of the null allele at the complement C4b locus in autism. Clin Exp Immunol 83: 438-440.
51. Odell D, Maciulis A, Cutler A, Warren L, McMahon WM, et al. (2005) Confirmation of the association of the C4B null allelle in autism. Hum Immunol 66: 140-145.

52. Mostafa GA, Shehab AA (2010) The link of C4B null allele to autism and to family history of autoimmunity in Egyptian autistic children. $\mathrm{J}$ Neuroimmunol 223: $115-119$ 